\title{
A Framework for Performance Monitoring in Agrifood Supply Chains via IoT Sensors
}

\author{
Gersi Sula, Dimitrios Bechtsis, Naoum Tsolakis
}

\begin{abstract}
The Internet of Things (IoT) is being applied in everyday operations across multiple industrial sectors. Sensing, transmitting and processing data in real time seems more feasible owing to the advancements in sensors and analytics capabilities. The value of data and information is evidently pertinent to the food and agricultural sector as commodities are vulnerable to physical and environmental disturbances. Key considerations arising from ensuring agrifood quality and nutritional value include companies' profitability, provision of fresh and quality supplies to consumers, improved inventory management and demand monitoring across the respective supply chains, and immediate and effective interventions during disruptions and risks to ensure resilience and continuity of operations. The technological progress over sensors and microsensors, along with the IoT, enables the tracing of products and the 24/7 monitoring of agrifood SCs. Data can be stored and processed in order to provide information and assist to the decision-making process.
\end{abstract}

Index Terms - agrifood supply chains, Internet of Things, sensors, performance assessment.

\section{INTRODUCTION}

In the past centuries, the provision and accessibility to food supplies was detrimental for the wellbeing of communities. Traditional activities like animal hunting and commodities' cultivation were basic for ensuring food supplies. Today, food systems have been industrialized while automated food processes effectively and efficiently provide agrifood products to the Supply Chain (SC) ecosystem. The industrialization and digitalization potential of food systems provides space for creative thinking, design, produce and use of innovative technologies to support business excellence and provide added value to food system stakeholders. The food industry has entered the Agriculture 4.0 era where automation and technology help create a global ecosystem directly linked agricultural production activities to downstream processing, distribution, retailing and consumption for crafting well-coordinated and intertwined food supply networks of increased operational performance.

Gersi Sula, Department of Industrial Engineering and Management, International Hellenic University, Thessaloniki, Greece.

Dimitrios Bechtsis, Department of Industrial Engineering and Management, International Hellenic University, Thessaloniki, Greece.

Naoum Tsolakis, Department of Supply Chain Management, International Hellenic University, Thessaloniki, Greece.

\section{FRAMEWORK}

\section{A. Literature Evidence}

Technological developments made significant contributions to the suppling, cultivation, production, harvesting, packaging, transportation, distribution and retailing echelons of a SC. In the SC there are many singleton businesses and corporations whose ultimate objectives is economical profit and at the same time customers' satisfaction. So, it is vital for these organizations to effectively collaborate with other parties, since their success is determined by the success all the stakeholders of the SC.

The higher the stakeholders' number in a SC, the more challenging it is for them to collaborate. A great, continuous and consciousness effort is required to team up and perform at the highest level. The necessity for optimal performance of the SC under all conditions has led to the development and implementation of modern technologies such as Internet of Things (IoT) and low energy high performance sensors.

\section{B. Supply Chain Mapping}

SC mapping is decisive to any organization, whether it is a domestic or an international one. A typical SC entails resources and operations that contribute to the movement of commodities from suppliers to the clients and vice versa [1]. However, monitoring all these SC activities, i.e., supply and delivery of necessary materials, information about schedules, stocks etc. and other factors is getting complicated at an operational basis.

Hence, it is crucial for organizations to manage network activities through visualizations which can help in monitoring the performance of the SC and make adjustments in order to be always on the right track [2]. This is where SC mapping is serviceable. SC mapping is about visual maps that highlight the commercial activities between customers and suppliers. SC maps display the connections and flows that are eventuating from all partners and their operations. Transport, warehousing, retailing, supply etc. are included as well.

The whole SC system is affected in regards of evaluation, analysis and assessment. The primary reasons for this are the large number of partners that take place in the SC, the complexity of data flow, the concomitance of various aspects and opinions to deal with criticalities and the irregularity in food products.

In order to assess a SC, a Performance Measurement System (PMS) is required. It can provide the requirement information for monitoring, evaluating, controlling and feedback function for management related to vital 


\section{A Framework for Performance Monitoring in Agrifood Supply Chains via IoT Sensors}

operations. Moreover, it can boost enterprises to seek improvement constantly and achieve their strategic objectives. Notwithstanding the benefits associated to evaluating SC performance, a range of issues relating to PMSs in a SC occur due to the lack of strategy focus and the large amount of financial measures. A SC system requires the orchestration of diverse organizations which typically have individual targets and goals; however, for the assessment of a SC's performance it is necessary to have an integrated view since global rather local optimization of the entire chain is necessary.

It is indispensable for a SC to clearly mark a group of Key Performance Indicators (KPIs) that will assist its design, planning, evaluation, analysis, control and management [3]. KPIs are a bundle of performance measures signify the degree at which an organization is achieving key objectives effectively.

KPIs apart from helping an organization to obtain operational and strategic improvement, also offer the chance to weight up accomplishments to similar organizations. To be compelling, a KPI must be: (i) quantifiable and clear (ii) transmissible and interpretable throughout a corporation's departments (iii) key issue to achieving specific goals and (iv) operant to the Line of Business or assignment.

The major challenge is the plethora of KPIs introduced in the extant literature. Therefore, the KPIs' selection is challenging and shall be meticulous in order to ultimately measuring an aspect that aligns with the goals of the corporation. To this effect, a fundamental research question arises: How should the right KPIs for the organization be selected?

The most suitable way to achieve this by examining and comprehending the majority of the most important KPIs. Through a full-on exam can be obtained a better understanding of which KPIs are particular to each organization and which ones will not be useful.

According to ClearPoint Strategy [8], KPIs can be categorized into four general groups based on their focus on: (i) financial aspects; (ii) customers; (iii) processes; and (iv) people.

Digitalization is the process of using digital technologies across industries to modify or create new business processes, enhance working culture, and foster effective end-user experiences. The objective is to meet evolving technology, business, and market requirements more effectively. Digitalization spans across traditional roles of operations, sales, marketing, and customer service and creates value in numerous ways. It includes the entire gamut of using smarter applications and enhanced experiences to manage businesses and engage with customers using digital technology to their advantage. Indicative benefits of digital transformation in manufacturing include: (i) increased operational efficiency; (ii) improved ability to innovate; (iii) cost reduction; (iv) data-driven insights; (v) better collaboration and consolidation; and (vi) shorter time-to-market.

The main difference between the $1^{\text {st }}$ and the $2^{\text {nd }}$ industrial revolution was the use of steam power though water to dehumanize production and the use of electricity for mass production. In the $3^{\text {rd }}$ revolution production was automated with the use of electronics and information technology. Currently, it is believed that the $4^{\text {th }}$ industrial revolution (Industry 4.0), the digital revolution, has been happening since the past 50-60 years. Its primary features include technologies that make less distinct the physical, digital and biological scope. Piece of the Industry 4.0 is large-scale Machine-to-Machine (M2M) communication and IoT.

The development of microsensors and cloud services in the last years, in combination with digitalization and IoT, offer conducive opportunities for the development and growth of Digital Supply Chain (DSC) systems. Digitalization comes in hand with a huge amount of unprocessed data stream and IoT makes it easy for such, mostly real-time, data to be processed promptly. With visualization tools the processed data can generate valuable information to guide and support the decision-making process across multiple echelons of SC operations.

\section{AGRIFOOD SUPPLY CHAINS: A DIGITALIZATION PERSPECTIVE}

\section{A. Mapping Methodologies}

Mapping an agrifood SC demands a detailed monitoring of all process. It is crucial to provide an exhaustive record of the SC processes, since this is the baseline structure that will shed lite to the digital transformation plans. Fresh food has a short shelf-life and is too sensitive in many aspects. This includes not only general factors like temperature or humidity that should be monitored in order to guarantee food quality, but also other environmental coefficients like oxygen or carbon dioxide levels etc.

Apart from information related to the state of the food, digitalization offers details regarding the raw materials that are used, the condition, the quality and the amount of them. Food transparency will make information more accessible in all stages of the SC.

Error! Reference source not found. presents a general framework related to the mapping of an agrifood SC. For ease of understanding it is considered a single-node chain. SCs are multi-node systems and products arrive to each client from various suppliers who also serve as suppliers to many clients in other echelons or even other SC ecosystems.

The first stage of agrifood SC begins with the suppliers that provide farming inputs. They have a decisive role in the chain that will determine quality of the final products. Providing the farmer with high quality soil fertilizers, herbicides, insecticides, fungicides, rodenticides, seeds, sprayers, tools and agricultural equipment sets a strong building block for the SC.

A farmer uses tools and equipment and starts the cultivation process by planting the seeds on the ground. This is the exact moment when he should focus on basic agricultural activities, namely watering, fertilizing, using pesticides and finally harvesting for collecting the products. Checking the humidity level of the ground and maintaining it within a specific range is vital for the appropriate cultivation of crops. In addition, knowing the exact time and location to apply fertilizers, along with the recommended volumes to be applied, regulates the chemical substances that are absorbed 
by the plants thus improving the nutritional and health and safety profile of the cultivated commodities. A unique farmer and field ID could be attributed and linked to the field's supplies and to the agrifood products.

The harvested food is packaged and transported with trucks in the factory for the creation of the final commodities. During this stage, it is very important to handle fresh food with appropriateness and preserve it to the highest quality by retaining its organoleptic characteristics. For example, temperature and humidity conditions should be periodically monitored. Higher or lower temperature for long time periods will result in food spoilage. There is a specific timeframe that should be retained before the food arrives to the next processing level, otherwise food spoilage is very likely. Other parameters that can be monitored include oxygen level, carbon dioxide level, light and vibrations.

When products arrive in the factory, the fresh and good conditioned products should be separated from the damaged and deteriorated ones. This separation will determine the processing path of each product. When all production processes are completed, the food will be packaged and reloaded into trucks for transport to cold storage warehouses. short period of time. During warehousing, optimum environmental conditions are required for preservation, including temperature, humidity, oxygen and carbon dioxide levels. What is more, the storage time should be checked frequently in order to avoid promoting the fresher products first or even worst letting them expire in the warehouse.

The distributor's role is to provide the retail shops with a range of products that can be sold within a specific timeframe. Usually, delivery routes are short and within the boundaries of an urban setting. This means that deliveries take a short time, thus the only parameters that have to be monitored are location and distribution time.

Retailer is the last step of the SC before the food reaches consumers. Retailers are responsible for the preservation of the food products, the price and the shelf life.

Consumers can easily access the products on local stores. Digital payment can help retail shops categorize the consumers depending on their nutritional preferences. By doing that they can make personalized offers to consumers and improve market sales.

In the cold storage facilities, the products will stay for a

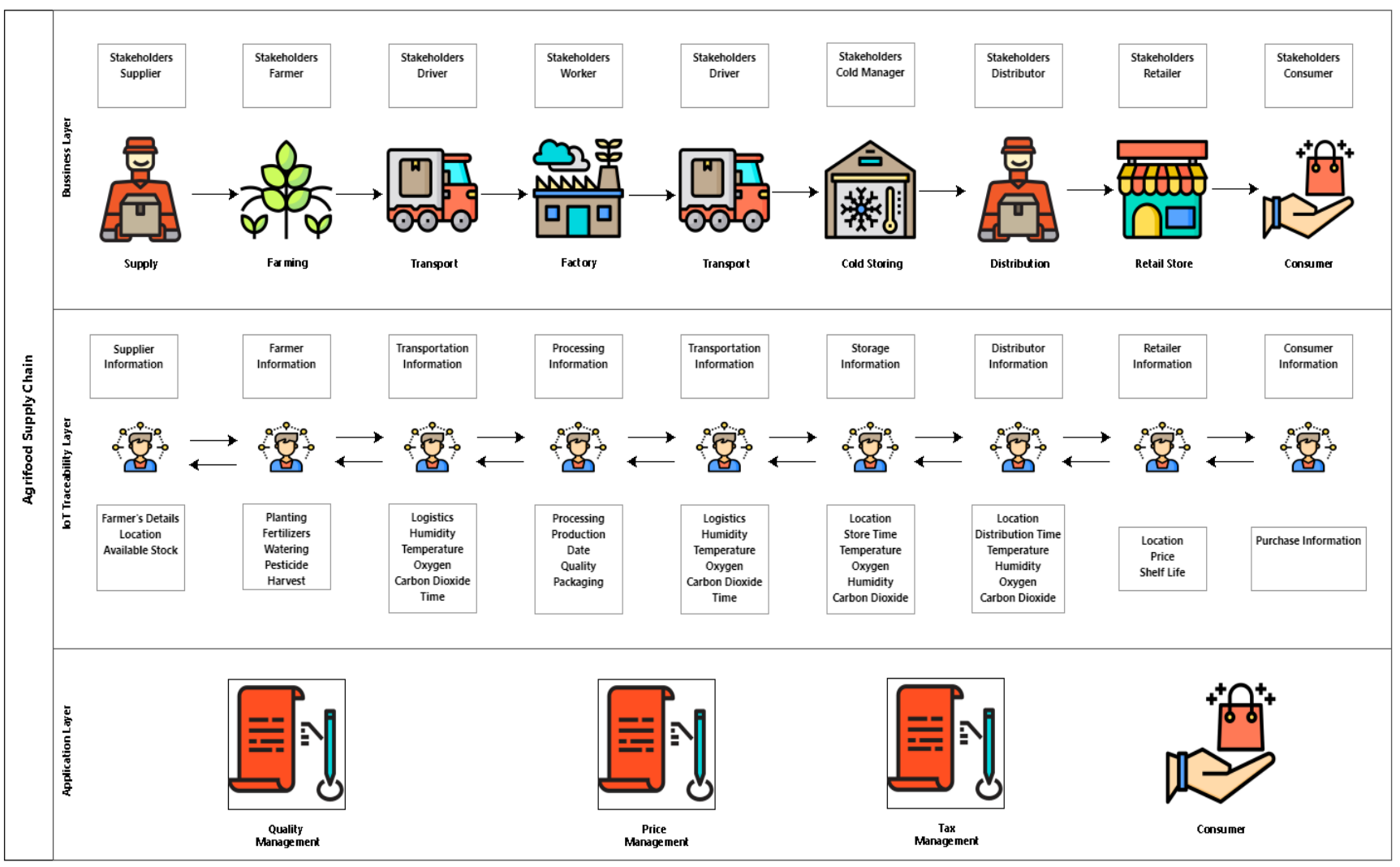

Fig.1 Agrifood Supply Chain Mapping [7]

\section{A. IoT and Sensors for Agrifood SC}

The integration of sensors and IoT platforms in agricultural activities has increased the data volume significantly [4]. In the farmland most of the sensors collect data from air, soil and water [5]. This includes temperature humidity, soil moisture, gas/particle concentration and radiation. Whether stations offer a combination of these measurements as well.

The two main technologies, that have been adopted and implemented by the IoT for sensing the environment are: (i) radio frequency identification (RFID); and (ii) wireless sensor networks (WSN).

Radio Frequency Identification (RFID) enables automatic detection and data acquisition using radio waves, a tag, and a reader. Tags are recognized in three categories. RFID passive tags depend on radio frequency energy transmitted from the reader to the tag to power the tag, so the do not use battery for power. They are widely used in SC, electronic tolls and passports. RFID active tags are supplied with a battery source and are able to communicate with a reader. They can carry 
external sensors to measure temperature, chemicals, pressure and other environmental conditions. Sectors like manufacturing, laboratories, hospitals and remote-sensing IT asset management have been using them mostly. RFID semi-passive tags have batteries to power their microchip while communicating by extracting power from the reader. RFID active and RFID semi-passive have higher cost than RFID passive [6].

Wireless sensor network (WSN) refers to devices that are spaced out in the area to monitor physical or environmental conditions. WSN can be combined with RFID to track temperature, location, movement, humidity etc. The advances in wireless communication and low power integrated circuits have dropped the technology cost, but ameliorated the efficiency of these applications. The main utilization of WSN is in the cold SC, where thermal and refrigerated packaging methods are mostly used. There are also examples of use of WSN in maintenance, manufacturing and tracking systems.

The most prominent IoT sensor categories are [9]:

1. Temperature sensors

2. Humidity sensors

3. Pressure sensors

4. Proximity sensors

5. Level sensors

6. Accelerometers

7. Gyroscope

8. Gas sensors

9. Infrared sensors

10. Optical sensors.

Despite the magnitude of IoT-related research and technological developments during the last years, there is lack of research and development for enterprise profitability. As every new technology, it brings on the current trends and reveals new challenges. The most distinguished are: (i) data management; (ii) data mining; (iii) privacy; and (iv) security [6].

\section{CONCLUSIONS}

In Agriculture 4.0 crucial farming objectives are reached by integrating all activities with the use of state-of-the-art technologies. Good practices like water saving, soil conservation, limiting carbon emissions and improving productiveness should be followed. On the one hand, digital technologies challenge the already established methodologies and provide new limits while maintain the quality levels. Furthermore, they reduce the levels of uncertainty, as they safeguard the repeatability of the methods. Real-time information from all the stages enables the SC to conclude to effective and efficient decisions and excel in the new digital SC ecosystem.

\section{REFERENCES}

I. V. Kozlenkova, G. T. M. Hult, D. J. Lund, J. A. Mena, and P Kekec, "The Role of Marketing Channels in Supply Chain Management," J. Retail., vol. 91, no. 4, pp. 586-609, 2015, doi: 10.1016/j.jretai.2015.03.003.

[2] W. Ho, T. Zheng, H. Yildiz, and S. Talluri, "Supply chain risk management: A literature review," Int. J. Prod. Res., vol. 53, no.
16, pp. 5031-5069, 2015, doi: 10.1080/00207543,2015.1030467. R. Manzini and R. Accorsi, "The new conceptual framework for food supply chain assessment," J. Food Eng., vol. 115, no. 2, pp. 251-263, 2013, doi: 10.1016/j.jfoodeng.2012.10.026.

[4] M. Lezoche, H. Panetto, J. Kacprzyk, J. E. Hernandez, and M. M E. Alemany Díaz, "Agri-food 4.0: A survey of the Supply Chains and Technologies for the Future Agriculture," Comput. Ind., vol. 117, p. 103187, 2020, doi: 10.1016/j.compind.2020.103187.

[5] J. Martín et al., "Review of IoT applications in agro-industrial and environmental fields," vol. 142, no. 118, pp. 283-297, 2017, doi 10.1016/j.compag.2017.09.015.

[6] I. Lee and K. Lee, "The Internet of Things (IoT): Applications, investments, and challenges for enterprises," Bus. Horiz., vol. 58, no. 4, pp. 431-440, 2015, doi: 10.1016/j.bushor.2015.03.008.

[7] Icons in Fig. 1 made by phatplus from www.flaticon.com

[8] ClearPointStrategy

https://www.clearpointstrategy.com/18-key-performance-indicators/

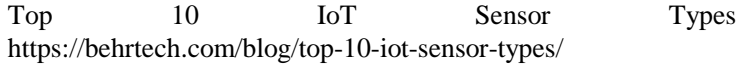

Gersi Sula is a graduate from the department of Industrial Engineering and Management of the International Hellenic University in Greece. He is interested in obtaining an academic career. His favorite science fields are Supply Chain Management, Internet of Things and Electric Cars, especially TESLA.

Dr. Dimitrios Bechtsis serves as Assistant Professor at the Industrial Engineering and Management Department of the International Hellenic University, Greece. His scientific interests indicatively cover the fields of Information Technology, Database Management Systems, Internet Of Things, Industry 4.0, Autonomous Vehicles, Digital/Sustainable Supply Chains and Agrifood Systems, while he is focusing on the incorporation of intelligent autonomous vehicles and systems in the supply chain ecosystem.

Dr. Naoum Tsolakis serves as an Assistant Professor at the Department of Supply Chain Management, International Hellenic University, Greece. His main research and practice interests are in the areas of simulation modelling and analysis of sustainable supply chain design and management in the circular economy era, along with intelligent autonomous systems for the industrial manufacturing, agrifood and pharmaceutical sectors. He has published his research work in acknowledged peer-reviewed scientific journals and in national and international conference proceedings. 